\title{
Hypothermia among trauma patients in the Emergency Department (ED): a review of documentation and management
}

\author{
Lucy V Harten-Ash*, Anthony Hudson \\ From London Trauma Conference 2013 \\ London, UK. 10-13 December 2013
}

\section{Background}

As a component of the lethal triad in trauma; hypothermia is associated with a significantly worse outcome. It is an independent indicator of mortality, and early recognition and aggressive management is therefore critically important. St. Georges is a major trauma centre and currently sees around 120 trauma patients per month. We designed an audit to determine our current practice of temperature measurement in trauma, and to evaluate our management of hypothermia in trauma.

\section{Method}

A retrospective audit of 93 case notes. Data was collected from all patients triaged to the ED as "Major trauma" during a three month period (October-December 2012 inclusive).

\section{Results}

$24 \%$ of trauma patients arrived with a pre-hospital temperature recorded. $67 \%$ had a primary survey temperature; of these $31 \%$ had no further temperature recorded. $17 \%$ of patients did not have any recorded temperatures during their time in the ED.

$37 \%$ had a documented temperature of $<36$ whilst in the ED.

$52 \%$ of patients had a warming method documented.

Of the hypothermic patients; normothermia was achieved in $44 \%$. 22\% left the ED with a greater temperature than on arrival but remained hypothermic. In $3 \%$ there was a documented fall in temperature.

\section{Discussion}

Hypothermia is common among our trauma patients. We feel that it is currently undervalued by our trauma team members. There is substantial room for improvement in our recording of temperatures. We are currently achieving normothermia in less than half of the hypothermic trauma patients.

Since our audit we have provided education on the significance of hypothermia and how to manage it in trauma. We have acquired a heated mattress for use in these patients. We have written a "Temperature in Major Trauma" guideline, and amended the trauma pro-forma to increase compliance with regular measurement, and to improve management of hypothermia.

Published: 7 July 2014

\section{References}

1. Martin S, et al: Injury associated hypothermia; An Analysis of the 2004 National Trauma Data Bank. Shock 2005, 24:114-118.

2. Peng, et al: Hypothermia in Trauma Patients. J Am Coll Surg 1999, 188:685.

3. Tsuei B, Kearney P: Hypothermia in the trauma patient. Injury 2004 $35: 7-15$.

\section{doi:10.1186/1757-7241-22-S1-P10}

Cite this article as: Harten-Ash and Hudson: Hypothermia among trauma patients in the Emergency Department (ED): a review of documentation and management. Scandinavian Journal of Trauma, Resuscitation and Emergency Medicine 2014 22(Suppl 1):P10. 